\title{
Natural Agents against Bovine Mastitis Pathogens
}

\author{
Zorana Kovačević $^{1, * \mathbb{D}}$, Miodrag Radinović ${ }^{1}$, Ivana Čabarkapa ${ }^{2}$, Nebojša Kladar ${ }^{3}$ and Biljana Božin ${ }^{3}$ \\ 1 Department of Veterinary Medicine, Faculty of Agriculture, University of Novi Sad, \\ Trg Dositeja Obradovica 8, 21000 Novi Sad, Serbia; miodrag.radinovic@polj.uns.ac.rs \\ 2 Institute of Food Technology, University of Novi Sad, Bulevar cara Lazara 1, 21000 Novi Sad, Serbia; \\ ivana.cabarkapa@fins.uns.ac.rs \\ 3 Center for Medical and Pharmaceutical Investigations and Quality Control/Department of Pharmacy, \\ Faculty of Medicine, University of Novi Sad, Hajduk Veljkova 3, 21000 Novi Sad, Serbia; \\ nebojsa.kladar@mf.uns.ac.rs (N.K.); biljana.bozin@mf.uns.ac.rs (B.B.) \\ * Correspondence: zorana.kovacevic@polj.edu.rs
}

Citation: Kovačević, Z.; Radinović, M.; Čabarkapa, I.; Kladar, N.; Božin, B. Natural Agents against Bovine Mastitis Pathogens. Antibiotics 2021, 10, 205. https://doi.org/10.3390/ antibiotics 10020205

Academic Editor: William N. Setzer

Received: 2 January 2021

Accepted: 13 February 2021

Published: 19 February 2021

Publisher's Note: MDPI stays neutral with regard to jurisdictional claims in published maps and institutional affiliations.

Copyright: (C) 2021 by the authors. Licensee MDPI, Basel, Switzerland. This article is an open access article distributed under the terms and conditions of the Creative Commons Attribution (CC BY) license (https:// creativecommons.org/licenses/by/ $4.0 /)$.

\begin{abstract}
Bovine mastitis is the most widespread and economically important disease worldwide. The present study aimed to determine bioactive compounds in two essential oils (EOs) from wild (Thymus serpyllum) and common thyme (Thymus vulgaris) and to assess the antioxidant potential as well as antibacterial efficacy of the EOs against mastitis-associated bacteria. The study also included antibiotic susceptibility tests. The strains were previously isolated from lactating animals with clinical and subclinical mastitis. The antioxidant potential of the commercial EOs of wild and common thyme was evaluated by five in vitro assays. The antibacterial activity was performed using the microdilution technique, while antibiotic susceptibility testing was performed by the Kirby-Bauer disc diffusion method. The dominant compound in wild thyme was thymol (45.22\%), followed by $p$-cymene $(23.83 \%)$ and $\gamma$-terpinene $(3.12 \%)$, while in common thyme, it was thymol (54.17\%), followed by $\gamma$-terpinene (22.18\%) and $p$-cymene (16.66\%). Among the fourteen mastitisassociated bacteria, strain IX Streptococcus spp. ( $\beta$-hemolytic) was the most sensitive to the tested EOs (minimum inhibitory concentration (MIC)/minimal bactericidal concentration (MBC) were 0.78/1.56 and $0.39 / 0.78 \mathrm{mg} / \mathrm{mL}$ for T. serpyllum (TS) and T. vulgaris (TV), respectively). Regarding Streptococcus spp. $\beta$ heamoliticus, MICs for TS ranged from 0.78 to $1.56 \mathrm{mg} / \mathrm{mL}$, while for the same oil, MBCs ranged from 1.56 to $12.5 \mathrm{mg} / \mathrm{mL}$. In the case of T. vulgaris, MICs ranged from 0.39 to $3.125 \mathrm{mg} / \mathrm{mL}$, while MBCs ranged from 3.125 to $6.25 \mathrm{mg} / \mathrm{mL}$. TV is more active against E. coli, E. sakazakii, and Streptococcus spp., while it is less effective against Staphylococcus spp. than TS. The study revealed that the tested EOs possess remarkable antioxidative and antibacterial activities and could be used in the development of pharmaceutical formulation as an alternative to conventional mastitis therapy.
\end{abstract}

Keywords: antibacterial activity; essential oil; mastitis causing bacteria; antioxidant; thymol; antibiotics

\section{Introduction}

The economic rise of the dairy market all over the world with the importance of delivering healthy and safety dairy products highlights the importance of managing milk production in a secure and sustainable manner [1-3]. In Serbia, milk production is organized in two different systems; small household farms with ten to twenty animals and large farms counting several hundred to several thousand cows [4].

The most common problems influencing animals' health in both production methods are those related to the health status of the mammary gland [5]. Actually, the occurrence of mastitis is highly frequent and, according to the type of clinical manifestation, this disease has clinical and subclinical classifications that occur simultaneously [6,7]. The etiology of mastitis is complex, and both mechanical and chemical factors that can be attributed to omissions in the way of housing and the procedure of milking cows certainly could contribute to the development of this disease [8]. This problem is more represented on 
large farms where little human labor is employed. Besides the etiology of mastitis, microbiological factors are more important, dominant bacterial causes [5]. While intramammary administration implies application of antibiotics directly in mammary gland through teat channel in order to achieve their effect locally in the gland, parenteral administration is application where the digestive tract is bypassed (e.g., intramuscularly, subcutaneously, intravenously) in order to achieve systemic effect including mammary gland tissue.

In Serbia, the most common causative agents of mastitis are Staphylococcus aureus and Streptococcus agalactiae, and recently E. coli, while Klebsiella spp., coagulase-negative staphylococci and Streptococcus uberis are becoming more and more common [5].

The prevalence of bovine mastitis resulted in the extensive use of antibiotics, intramammary and parenterally [9]. Erskine, et al. [10] revealed that $90 \%$ of antibiotic residues in milk are a consequence of mastitis therapy. Hence, the use of antibiotics in the treatment of mastitis has some negative consequences, such as entry of antibiotic residues into the human food chain [11], with the possibility of antibiotic-resistant bacteria strains transmission [12]. Additionally, as a negative consequence, increasing resistance of microorganisms to antibiotics causes the degree of intramammary infections cure to be at a very low level. Moreover, the degree of cure in the case of Staphylococcus aureus is 20 to $75 \%$ [13].

Control of udder health is important for the dairy production chain in light of food safety issues, with control of udder pathogens being the most important in the reduction of foodborne illness and giving healthy dairy food $[14,15]$. Besides, development and spread of resistance to antibiotics as a consequence of mastitis treatment represent a public health threat to consumers as a global problem, influencing both human and animal health. Faced with the continued growth of antibiotic-resistant pathogens, there is a need for finding novel antimicrobial compounds [16].

Considering the facts mentioned above, many studies tend to develop alternative treatments with bioactive plant-derived products (PDPs), such as plant extracts, essential oils (EOs), hydrolates, oleoresins, and so on $[17,18]$. Many attempts have been made to test the potential role of EOs and their active compounds to combat antibiotic resistance in bacteria [19].

Furthermore, although many aromatic plants and essential oils are tested, especially for antioxidant and antimicrobial activity, plants belonging to the genus Thymus, among others, are of special interest regarding the presence of notable amounts of thymol and carvacrol, being strong antioxidant and antimicrobial agents [20-23].

Moreover, these studies highlighted a high scientific interest whereby EOs warrant special attention as they are recognized as safe. Besides, EOs do not increase antibiotic resistance during long-term usage, which represents their main advantage [24]. Additionally, synergism between plant metabolites and antibiotics has been described by Hemaiswarya, et al. [25], suggesting the use of EOs as in combination with antibiotics. Furthermore, EOs were characterized by low mammalian toxicity, low environmental effects, and wide public acceptance.

However, it is well known that several chemotypes of Thymus serpyllum have been described until now [26-28]; as differences in chemical composition have a notable influence on investigated biological activities, new data are of great importance. Besides, it is well known that EOs' chemical composition, contributing to their medicinal value and being responsible for the biological properties, highly depends on many factors such as geographical and climatic conditions, harvesting, isolation techniques, as well as storage [29,30].

In line with those mentioned above, this study aimed to evaluate the effectiveness of EOs of common (Thymus vulgaris L.) and wild thyme (Thymus serpyllum L.) against mastitis-associated pathogens in Serbia.

\section{Results}

\subsection{Bacteriological Testing of Milk Samples}

Bacteriological testing was performed on a total of 31 milk samples, while pathogens were isolated in $21(67.74 \%)$ samples. The isolated pathogens were the most common 
mastitis pathogens, including Streptococcus spp. $\beta$ heamoliticus (Strep_bh), E. coli (E_c), Enterobacter sakazakii (E_s), Klebsiella oxytoca (K_o), Staphylococcus aureus (Staph_a), Staphylococcus spp. coagulase negative (Staph_cn), Streptococcus dysgalactiae (Strep_d), Streptococcus spp. (Strep), and Streptococcus uberis (Strep_u).

The most common among the pathogens was E. coli, which was identified in six samples (19.35\%), followed by five (16.13\%) samples with Streptococcus spp., while Staphylococcus spp. coagulase negative, Streptococcus uberis, Streptococcus dysgalactiae, Klebsiella oxytoca, and Enterobacter sakazakii were found in one sample each (3.23\%) (Figure 1).

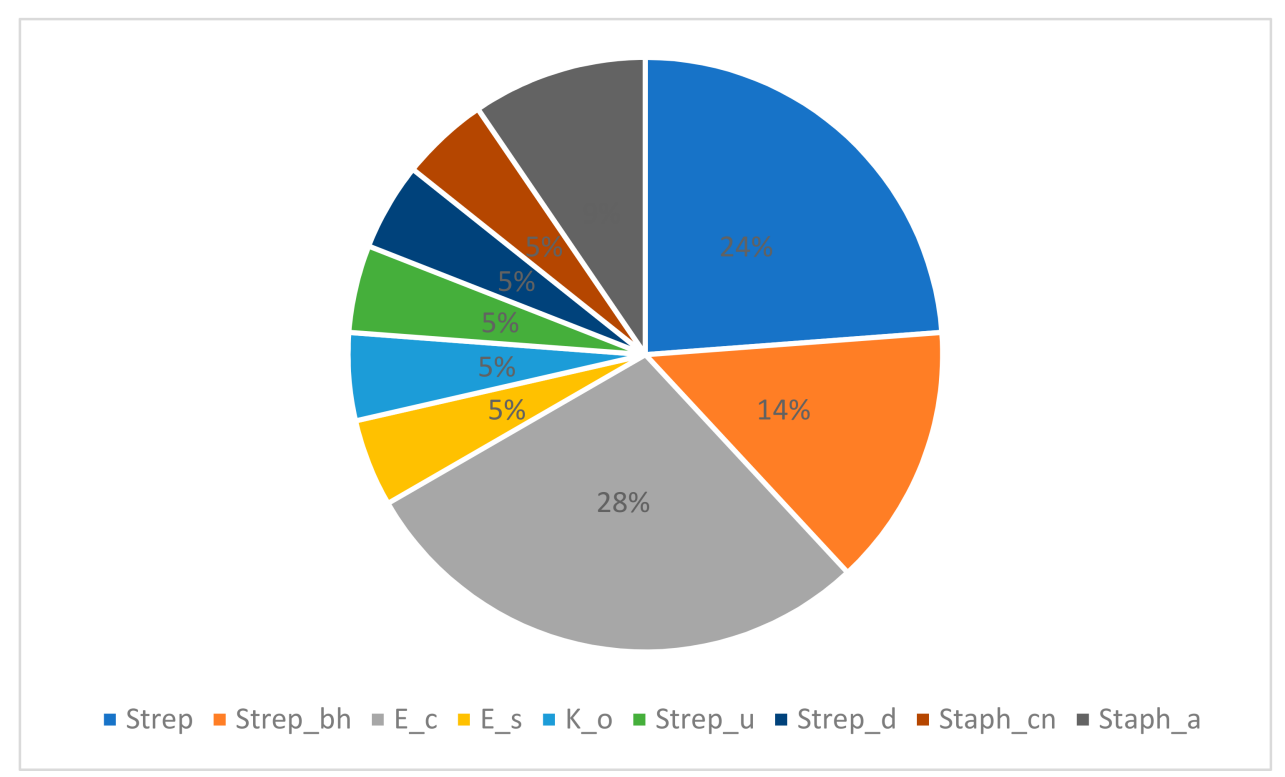

Figure 1. The proportion (\%) of the evaluated bacterial strains in the collected samples.

\subsection{Antibiotic Susceptibility Testing of Mastitis-Associated Bacteria}

Antibiotic susceptibility patterns for the analyzed 16 mastitis-associated bacteria are shown in Table 1. Antibiotics included in the testing are amoxycillin (AMX), ampicillin (AMP), ceftriaxone (CRO), enrofloxacin (ENR), erythromycin (ERY), lincomycin (LIN), neomycin (NEO), penicillin (PEN), streptomycin (STR), tetracycline (TET), amoxicillin/clavulanic acid (AMC), novobiocin (NB), trimethoprim/sulfamethoxazole (SXT), and cloxacillin (CLO). In Serbia, the most used antibiotics in mastitis therapy are penicillin, streptomycin, gentamicin, tetracycline, cephalexin, sulfonamides, and enrofloxacin [31].

Table 1. Antibiotic susceptibility patterns for the mastitis-associated bacteria (S—sensitive, I-intermediate, $\mathrm{R}$-resistant). AMX, moxycillin; AMP, ampicillin; CRO, ceftriaxone; ENR, enrofloxacin; ERY, erythromycin; LIN, lincomycin; NEO, neomycin; PEN, penicillin; STR, streptomycin; TET, tetracycline; AMC, amoxicillin/clavulanic acid; NB, novobiocin; SXT, trimethoprim/sulfamethoxazole; CLO, cloxacillin.

\begin{tabular}{|c|c|c|c|c|c|c|c|c|c|c|c|c|c|c|c|}
\hline Bacterial Strains Culture & AMX & AMP & CRO & ENR & ERY & GEN & LIN & NEO & PEN & STR & TET & AMC & NB & SXT & CLO \\
\hline Streptococcus spp. $\beta$ heamoliticus & S & S & S & $S$ & $S$ & $\mathrm{R}$ & S & $\mathrm{R}$ & $\mathrm{R}$ & $S$ & $S$ & $S$ & $\mathrm{~S}$ & $\mathrm{R}$ & $\mathrm{R}$ \\
\hline Staphylococcus spp. & $\mathrm{R}$ & $\mathrm{R}$ & $\mathrm{R}$ & $\mathrm{R}$ & $\mathrm{R}$ & I & $\mathrm{R}$ & $\mathrm{R}$ & $\mathrm{R}$ & $S$ & $\mathrm{R}$ & $\mathrm{R}$ & $\mathrm{R}$ & $\mathrm{R}$ & $\mathrm{R}$ \\
\hline Staphylococcus spp. & $\mathrm{R}$ & $\mathrm{R}$ & $\mathrm{R}$ & $\mathrm{R}$ & $\mathrm{R}$ & $\mathrm{I}$ & $\mathrm{R}$ & $\mathrm{R}$ & $\mathrm{R}$ & $S$ & $\mathrm{R}$ & $\mathrm{R}$ & $\mathrm{R}$ & $\mathrm{R}$ & $\mathrm{R}$ \\
\hline $\begin{array}{l}\text { Staphylococcus spp. } \\
\text { coagulase negative }\end{array}$ & S & S & I & S & S & S & S & S & $\mathrm{R}$ & S & S & S & $\mathrm{S}$ & S & $\mathrm{R}$ \\
\hline Staphylococcus spp. & $\mathrm{R}$ & $\mathrm{R}$ & $\mathrm{R}$ & $\mathrm{R}$ & I & $S$ & $\mathrm{R}$ & $\mathrm{R}$ & $\mathrm{R}$ & S & $\mathrm{R}$ & $\mathrm{R}$ & $\mathrm{R}$ & $\mathrm{R}$ & $\mathrm{R}$ \\
\hline Streptococcus spp. $\beta$ heamoliticus & I & $\mathrm{R}$ & $S$ & $S$ & $\mathrm{R}$ & $S$ & $\mathrm{R}$ & $S$ & $\mathrm{R}$ & $S$ & I & $S$ & $\mathrm{I}$ & $S$ & $\mathrm{R}$ \\
\hline E. coli & $\mathrm{R}$ & $\mathrm{R}$ & $\mathrm{R}$ & S & $\mathrm{R}$ & $S$ & $\mathrm{R}$ & S & $\mathrm{R}$ & $S$ & $\mathrm{R}$ & $\mathrm{R}$ & $\mathrm{R}$ & S & $\mathrm{R}$ \\
\hline E. coli & $\mathrm{R}$ & $\mathrm{R}$ & $\mathrm{R}$ & $S$ & $\mathrm{R}$ & $S$ & $\mathrm{R}$ & $S$ & $\mathrm{R}$ & $S$ & I & $\mathrm{R}$ & $\mathrm{R}$ & $S$ & $\mathrm{R}$ \\
\hline Streptococcus spp. $\beta$ heamoliticus & $\mathrm{R}$ & $\mathrm{R}$ & S & S & $\mathrm{R}$ & S & $\mathrm{R}$ & S & $\mathrm{R}$ & S & $\mathrm{R}$ & S & $\mathrm{R}$ & $\mathrm{R}$ & $\mathrm{R}$ \\
\hline Klebsiella oxytoca & $\mathrm{R}$ & $\mathrm{R}$ & S & $S$ & $\mathrm{R}$ & $S$ & $\mathrm{R}$ & $S$ & $\mathrm{R}$ & $S$ & $\mathrm{R}$ & $\mathrm{R}$ & $\mathrm{R}$ & $S$ & $\mathrm{R}$ \\
\hline
\end{tabular}


Table 1. Cont.

\begin{tabular}{cllllllllllllllll}
\hline Bacterial Strains Culture & \multicolumn{1}{c}{ AMX AMP CRO } & ENR & ERY & GEN & LIN & NEO & PEN & STR & TET & AMC NB & SXT & CLO \\
\hline E. coli & $\mathrm{R}$ & $\mathrm{R}$ & $\mathrm{R}$ & $\mathrm{S}$ & $\mathrm{R}$ & $\mathrm{S}$ & $\mathrm{R}$ & $\mathrm{S}$ & $\mathrm{R}$ & $\mathrm{S}$ & $\mathrm{I}$ & $\mathrm{R}$ & $\mathrm{R}$ & $\mathrm{S}$ & $\mathrm{R}$ \\
Staphylococcus spp. & $\mathrm{R}$ & $\mathrm{R}$ & $\mathrm{I}$ & $\mathrm{S}$ & $\mathrm{R}$ & $\mathrm{S}$ & $\mathrm{I}$ & $\mathrm{R}$ & $\mathrm{R}$ & $\mathrm{S}$ & $\mathrm{R}$ & $\mathrm{S}$ & $\mathrm{R}$ & $\mathrm{R}$ & $\mathrm{R}$ \\
E. coli & $\mathrm{R}$ & $\mathrm{R}$ & $\mathrm{R}$ & $\mathrm{S}$ & $\mathrm{R}$ & $\mathrm{S}$ & $\mathrm{R}$ & $\mathrm{S}$ & $\mathrm{R}$ & $\mathrm{S}$ & $\mathrm{R}$ & $\mathrm{R}$ & $\mathrm{R}$ & $\mathrm{S}$ & $\mathrm{R}$ \\
Enterobacter sakazakii & $\mathrm{R}$ & $\mathrm{R}$ & $\mathrm{R}$ & $\mathrm{S}$ & $\mathrm{R}$ & $\mathrm{S}$ & $\mathrm{R}$ & $\mathrm{S}$ & $\mathrm{R}$ & $\mathrm{S}$ & $\mathrm{S}$ & $\mathrm{R}$ & $\mathrm{R}$ & $\mathrm{S}$ & $\mathrm{R}$ \\
Staphylococcus aureus & $\mathrm{I}$ & $\mathrm{R}$ & $\mathrm{S}$ & $\mathrm{S}$ & $\mathrm{S}$ & $\mathrm{S}$ & $\mathrm{S}$ & $\mathrm{S}$ & $\mathrm{R}$ & $\mathrm{S}$ & $\mathrm{S}$ & $\mathrm{S}$ & $\mathrm{S}$ & $\mathrm{S}$ & $\mathrm{R}$ \\
E. coli & $\mathrm{I}$ & $\mathrm{R}$ & $\mathrm{S}$ & $\mathrm{S}$ & $\mathrm{R}$ & $\mathrm{S}$ & $\mathrm{R}$ & $\mathrm{S}$ & $\mathrm{R}$ & $\mathrm{S}$ & $\mathrm{I}$ & $\mathrm{S}$ & $\mathrm{R}$ & $\mathrm{S}$ & $\mathrm{R}$ \\
Streptococcus uberis & $\mathrm{S}$ & $\mathrm{S}$ & $\mathrm{I}$ & $\mathrm{S}$ & $\mathrm{I}$ & $\mathrm{S}$ & $\mathrm{R}$ & $\mathrm{R}$ & $\mathrm{R}$ & $\mathrm{S}$ & $\mathrm{S}$ & $\mathrm{S}$ & $\mathrm{R}$ & $\mathrm{R}$ & $\mathrm{R}$ \\
E. coli & $\mathrm{I}$ & $\mathrm{R}$ & $\mathrm{S}$ & $\mathrm{S}$ & $\mathrm{R}$ & $\mathrm{S}$ & $\mathrm{R}$ & $\mathrm{S}$ & $\mathrm{R}$ & $\mathrm{S}$ & $\mathrm{S}$ & $\mathrm{S}$ & $\mathrm{R}$ & $\mathrm{S}$ & $\mathrm{R}$ \\
Staphylococcus aureus & $\mathrm{I}$ & $\mathrm{R}$ & $\mathrm{S}$ & $\mathrm{S}$ & $\mathrm{S}$ & $\mathrm{S}$ & $\mathrm{S}$ & $\mathrm{S}$ & $\mathrm{R}$ & $\mathrm{S}$ & $\mathrm{S}$ & $\mathrm{S}$ & $\mathrm{S}$ & $\mathrm{S}$ & $\mathrm{R}$ \\
Streptococcus dysgalactiae & $\mathrm{S}$ & $\mathrm{R}$ & $\mathrm{R}$ & $\mathrm{S}$ & $\mathrm{I}$ & $\mathrm{I}$ & $\mathrm{R}$ & $\mathrm{R}$ & $\mathrm{R}$ & $\mathrm{S}$ & $\mathrm{R}$ & $\mathrm{S}$ & $\mathrm{I}$ & $\mathrm{R}$ & $\mathrm{R}$ \\
Staphylococcus spp. & $\mathrm{S}$ & $\mathrm{S}$ & $\mathrm{S}$ & $\mathrm{S}$ & $\mathrm{S}$ & $\mathrm{S}$ & $\mathrm{R}$ & $\mathrm{R}$ & $\mathrm{R}$ & $\mathrm{R}$ & $\mathrm{R}$ & $\mathrm{S}$ & $\mathrm{R}$ & $\mathrm{R}$ & $\mathrm{R}$ \\
\hline
\end{tabular}

Application of correspondence analysis (CA) on a dataset describing bactericidal potential of different antibiotics on bacteria isolated from the milk samples shows associations of different bacteria and the evaluated antibiotics in terms of bacteria resistance (R) or sensitivity (S). It must be stated that the results obtained for penicillin (PEN) and cloxacillin (CLO) were not included in statistical processing because of their uniformity. It was observed that the first three correspondent axes (CA1, CA2, and CA3) describe around $50 \%$ of the samples' variability (percentage of inertia for CA1, CA2, and CA3 was $22.14 \%, 17.83 \%$, and $9.31 \%$, respectively). The position of the evaluated bacteria cultures and antibiotics in the space defined by the first three correspondent axes (Figure 2) shows close association of E. coli (E_c), Klebsiella oxytoca (K_o) and Enterobacter sakazakii (E_s) in the negative part of CA1 and the positive part of CA2 as a result of resistance to erythromycin (ERY), amoxycillin (AMX), and amoxicillin/clavulanic acid (AMC), and sensitivity to neomycin (NEO) and trimethoprim/sulfamethoxazole (SXT). Furthermore, Streptococcus spp. (Strep) are localized in the negative part of CA1 and the negative part of CA2, which is closely related to resistance to SXT, NEO, enrofloxacin (ENR), tetracycline (TET), lincomycin (LIN), and ceftriaxone (CRO). Streptococcus spp. $\beta$-heamoliticus (Strep_bh) are sensitive to AMC, CRO, and ENR. Staphylococcus aureus are resistant to ampicillin (AMP), penicillin (PEN), and cloxacillin (CLO).

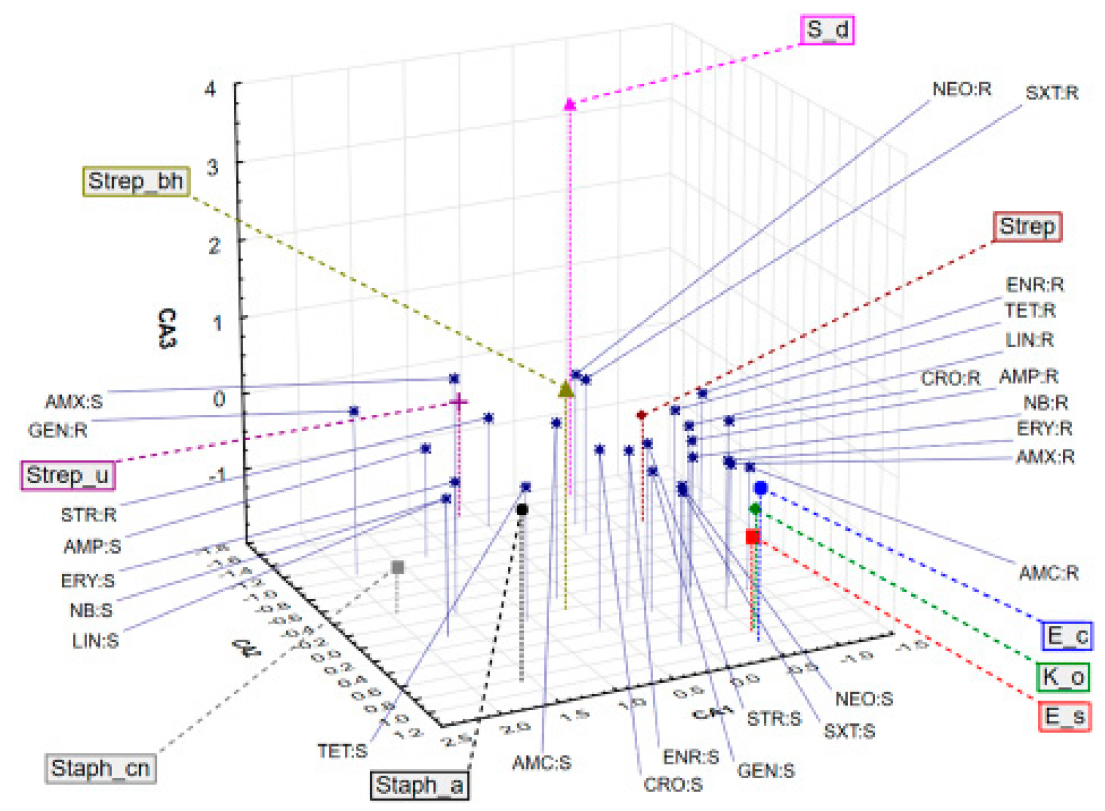

Figure 2. Position of the evaluated bacterial cultures and their sensitivity (S) or resistance (R) to antibiotics treatment in the space defined by the first three correspondent axes. 


\subsection{EOs' Chemical Composition Analysis}

Detailed chemical compositions of the tested wild (T. serpyllum) and common thyme (T. vulgaris) EOs are listed in Table 2. In the wild thyme EO, there are 19 identified compounds (accounting for $99.29 \%$ of total volatile compounds) and, in the common thyme EO, there are 25 compounds (accounting for $99.20 \%$ of total volatile compounds). In general, the compounds in both EOs are classified as monoterpenes, with predominance of aromatic oxygenated monoterpenes (51.49\% in T. vulgaris and $54.98 \%$ in T. serpyllum). The dominant compounds in T. serpyllum EO are thymol (54.17\%), $\gamma$-terpinene $(22.18 \%)$, and $p$-cymene $(16.66 \%)$. In T. vulgaris EO, the dominant compounds are thymol (45.22\%) and $p$-cymene $(23.83 \%)$, while the content of $\gamma$-terpinene is notably lower (3.12\%). Trans- $\beta$-caryophyllene, a sesquiterpene hydrocarbon, is the third main compound (4.04\%) in T. vulgaris EO.

Table 2. Chemical composition of T. serpyllum and T. vulgaris essential oils (EOs) (\%).

\begin{tabular}{|c|c|c|c|c|}
\hline Peak No. & Compounds & $\mathrm{RI}^{\mathrm{a}}$ & T. vulgaris & T. serpyllum \\
\hline \multicolumn{3}{|c|}{ Monoterpene Hydrocarbons } & 10.84 & 25.4 \\
\hline 1. & $\alpha$-Pinene & 937 & 1.51 & 0.18 \\
\hline 2. & Camphene & 952 & 1.67 & 0.19 \\
\hline 3. & $\beta$-Pinene & 978 & 0.21 & 2.15 \\
\hline 4. & $\beta$-Myrcene & 991 & 1.64 & 0.28 \\
\hline 5. & $\alpha$-Phellandrene & 1005 & 0.11 & 0.08 \\
\hline 6. & $\alpha$-Terpinene & 1017 & 0.87 & 0.13 \\
\hline 8. & Limonene & 1030 & 1.71 & 0.21 \\
\hline 12. & $\gamma$-Terpinene & 1060 & 3.12 & 22.18 \\
\hline \multicolumn{3}{|c|}{ Aromatic Monoterpene Hydrocarbons } & 23.83 & 16.66 \\
\hline 7. & p-Cymene & 1025 & 23.83 & 16.66 \\
\hline \multicolumn{3}{|c|}{ Oxygenated Monoterpenes } & 7.19 & 2.05 \\
\hline 9. & 1,8-Cineole & 1032 & 0.93 & 0.16 \\
\hline 10. & Linalool & 1099 & 2.55 & 0 \\
\hline 11. & Camphor & 1145 & 0.33 & 0.77 \\
\hline 13. & endo-Borneol & 1167 & 1.68 & 0 \\
\hline 14. & Terpinen-4-ol & 1177 & 1.42 & 0.07 \\
\hline 15. & Isomenthol & 1183 & 0 & 0.84 \\
\hline 16. & $\alpha$-Terpineol & 1189 & 0.23 & 0.03 \\
\hline 19. & Bornyl acetate & 1285 & 0.05 & 0.07 \\
\hline 26. & trans- $\beta$-Ionone & 1486 & 0 & 0.11 \\
\hline \multicolumn{3}{|c|}{ Aromatic Oxygenated Monoterpenes } & 51.49 & 54.98 \\
\hline 17. & $\begin{array}{c}\text { Isothymol methyl } \\
\text { ether }\end{array}$ & 1230 & 0.92 & 0 \\
\hline 18. & Thymol methyl ether & 1235 & 1.49 & 0 \\
\hline 20. & Thymol & 1291 & 45.22 & 54.17 \\
\hline 21. & Carvacrol & 1299 & 3.86 & 0.81 \\
\hline \multicolumn{3}{|c|}{ Sesquiterpene Hydrocarbons } & 4.91 & 0.2 \\
\hline 22. & $\alpha$-Cubebene & 1351 & 0.08 & 0 \\
\hline 23. & $\beta$-Cubenene & 1388 & 0.03 & 0 \\
\hline 24. & $\begin{array}{c}\text { trans- } \beta- \\
\text { Caryophyllene }\end{array}$ & 1419 & 4.04 & 0.12 \\
\hline 25. & Humulene & 1454 & 0.41 & 0.08 \\
\hline 27. & $\delta$-Cadinene & 1524 & 0.35 & 0 \\
\hline \multicolumn{3}{|c|}{ Oxygenated Sesquiterpenes } & 0.94 & 0 \\
\hline 28. & Caryophyllene oxide & 1581 & 0.94 & 0 \\
\hline \multicolumn{3}{|c|}{ Total of identified compounds (\%) } & 99.2 & 99.29 \\
\hline
\end{tabular}

\footnotetext{
a Retention indices (RI) relative to C9-C24 n-alkanes on the HP 5MS column.
} 


\subsection{EOs' Antioxidant Potential Evaluation}

The antioxidant potential of the tested EOs (T. vulgaris and T. serpyllum) and the positive control substances were evaluated in a series of in vitro tests (Table 3). All results, except those obtained in the ferric reduction antioxidant potential (FRAP) test, are presented as the inhibitory concentration $\left(\mathrm{IC}_{50}\right)$ values, representing the concentrations of the EOs and positive controls that caused $50 \%$ of neutralization, determined by linear regression analysis.

Table 3. Antioxidant potential of the investigated essential oils of T. serpyllum and T. vulgaris and positive control substances (AA — ascorbic acid; PG—propyl gallate; BHT—tert-butylated hydroxytoluene). FRAP, ferric reduction antioxidant potential; DPPH, 2,2-diphenyl-1-picrylhydrazyl; OH, hydroxyl; LP, lipid peroxidation.

\begin{tabular}{|c|c|c|c|c|}
\hline \multirow{3}{*}{ Samples } & \multicolumn{4}{|c|}{ Assay } \\
\hline & DPPH IC 50 & $\mathrm{OH} \mathrm{IC}{ }_{50}(\mu \mathrm{g} / \mathrm{mL})$ & $\mathrm{LP}_{\mathrm{IC}} \mathrm{C}_{50}$ & FRAP (mg AAE a /mL EO) \\
\hline & $\overline{X^{b}} \pm \mathrm{SD}^{\mathrm{c}}$ & $\bar{X} \pm \mathrm{SD}$ & $\bar{X} \pm \mathrm{SD}$ & $\bar{X} \pm \mathrm{SD}$ \\
\hline T. vulgaris & $14 \pm 0.85$ & $230 \pm 1.19$ & $19 \pm 1.02$ & $34.95 \pm 3.50$ \\
\hline T. serpyllum & $16 \pm 0.93$ & $170 \pm 2.02$ & $17 \pm 0.92$ & $29.00 \pm 2.90$ \\
\hline AA & I & $2003 \pm 0.39$ & I & I \\
\hline PG & $0.71 \pm 0.04$ & $9.07 \pm 0.59$ & I & I \\
\hline BHT & I & $0.03 \pm 0.01$ & $7.29 \pm 0.56$ & I \\
\hline
\end{tabular}

DPPH assay was employed to determine the ability of the tested EOs of common and wild thyme, as well as propyl gallate (PG), to act as donors of hydrogen atoms or electrons in the transformation of DPPH ${ }^{\bullet}$ into its reduced form DPPH-H reaction [32]. Although PG (propyl gallate) $(0.71 \mu \mathrm{g} / \mathrm{mL})$ exhibited very potent free radical scavenging capacity, both EOs were able to reduce the DPPH ${ }^{\bullet}$ into $\mathrm{DPPH}-\mathrm{H}$, reaching $50 \%$ of reduction $\left(\mathrm{IC}_{50}=16\right.$ for T. serpyllum and $14 \mu \mathrm{L} / \mathrm{mL}$ for T. vulgaris). The free radical scavenging capacity (RSC) of EOs for hydroxyl $(\mathrm{OH})$ radicals was evaluated by measuring the degradation of 2-deoxyribose with OH radicals, generated in the Fenton reaction [32]. Both EOs showed a lower RSC $\left(\mathrm{IC}_{50}=170\right.$ for $T$. serpyllum and $230 \mu \mathrm{g} / \mathrm{mL}$ for $T$. vulgaris, respectively) compared with the PG (propyl gallate) $(9.07 \mu \mathrm{g} / \mathrm{mL})$ and tert-butylated hydroxytoluene (BHT) $(0.03 \mu \mathrm{g} / \mathrm{mL})$ $\mathrm{IC}_{50}$ values, used as standard synthetic antioxidants. However, both of them exhibited protective effects on 2-deoxy-D-ribose degradation, although they were lower compared with ascorbic acid (AA) $(2.03 \mu \mathrm{g} / \mathrm{mL})$. Regarding the neutralization of NO, neither EO reached $50 \%$ of reduction. The testing of the ability of the examined EOs to protect the integrity of biological membranes containing lipids was evaluated through determination of lipid peroxidation (LP) inhibition potential, pointing to protective effects of the tested EOs ( $\mathrm{IC}_{50}=170$ for $T$. serpyllum and $190 \mu \mathrm{g} / \mathrm{mL}$ for T. vulgaris), but notably lower from those exhibited by BHT $(7.29 \mu \mathrm{g} / \mathrm{mL})$.

The FRAP test showed a notable antioxidant activity for both EOs (29 mg AAE/mL for T. serpyllum $\mathrm{EO}$ and $34.95 \mathrm{mg} \mathrm{AAE} / \mathrm{mL}$ for T. vulgaris $\mathrm{EO})$.

Comprehensive evaluation of the antioxidant potential in several test-systems showed no significant differences between the examined EOs samples $(\mathrm{F}(4,1)=58.82$, Wilks $=0.004$, $p=0.0974)$.

\subsection{EOs Effectiveness against Mastitis-Associated Bacteria}

EOs effectiveness against mastitis-associated bacteria was expressed as minimum inhibitory concentrations (MICs) and minimal bactericidal concentrations (MBCs) (Table 4). Among the fourteen mastitis-associated bacteria, strain IX Streptococcus spp. ( $\beta$-hemolytic) showed the most sensitivity to the tested EOs (MIC/MBC were $0.78 / 1.56$ and $0.39 / 0.78 \mathrm{mg} / \mathrm{mL}$ for T. serpyllum and T. vulgaris, respectively). Regarding Streptococcus spp. $\beta$ heamoliticus, MICs for T. serpyllum ranged from 0.78 to $1.56 \mathrm{mg} / \mathrm{mL}$, while for the same oil, MBCs ranged 
from 1.56 to $12.5 \mathrm{mg} / \mathrm{mL}$. In the case of T. vulgaris, MICs ranged from 0.39 to $3.125 \mathrm{mg} / \mathrm{mL}$, while MBCs ranged from 3.125 to $6.25 \mathrm{mg} / \mathrm{mL}$. TV is more active against E. coli, E. sakazakii, and Streptococcus spp., while it is less effective against Staphylococcus spp. than TS.

Table 4. Minimum inhibitory concentrations (MICs) and minimal bactericidal concentrations (MBCs) of T. serpyllum and T. vulgaris EOs against mastitis-associated pathogens.

\begin{tabular}{|c|c|c|c|c|}
\hline Sample & $\mathrm{TV} *(\mathrm{MIC})(\mathrm{mg} / \mathrm{mL})$ & $\mathrm{TV}^{*}(\mathrm{MBC})(\mathrm{mg} / \mathrm{mL})$ & $\mathrm{TS} * *(\mathrm{MIC})(\mathrm{mg} / \mathrm{mL})$ & $\mathrm{TS}^{* *}(\mathrm{MBC})(\mathrm{mg} / \mathrm{mL})$ \\
\hline 4 E. coli & 3.125 & 6.25 & 6.25 & 12.5 \\
\hline Enterobacter sakazakii & 3.125 & 6.25 & 6.25 & 12.5 \\
\hline $\begin{array}{l}\text { Streptococcus spp. } \\
\beta \text { heamoliticus }\end{array}$ & 0.39 & 0.78 & 1.56 & 3.125 \\
\hline $\begin{array}{l}\text { Streptococcus spp. } \\
\beta \text { heamoliticus }\end{array}$ & 0.78 & 1.56 & 1.56 & 3.125 \\
\hline $\begin{array}{c}\text { Streptococcus spp. } \\
\beta \text { heamoliticus }\end{array}$ & 0.39 & 0.78 & 0.78 & 1.56 \\
\hline Streptococcus spp. & 1.56 & 3.125 & 3.125 & 6.25 \\
\hline Streptococcus spp. & 0.78 & 1.56 & 3.125 & 6.25 \\
\hline Streptococcus spp. & 1.56 & 6.25 & 3.125 & 6.25 \\
\hline Staphylococcus spp. & 6.25 & 12.5 & 3.125 & 6.25 \\
\hline $\begin{array}{l}\text { Staphylococcus spp. } \\
\text { coagulase negative }\end{array}$ & 6.25 & 12.5 & 3.125 & 6.25 \\
\hline Klebsiella oxytoca & 1.56 & 6.25 & 3.125 & 6.25 \\
\hline
\end{tabular}

* T. serpyllum (TS) EO. ** T. vulgaris (TV) EO.

2.6. Interpretations of $M B C, M I C$, Thymus vulgaris, and Thymus serpyllum EOs in Relation to the Chemical Composition of the EOs

Application of principal components analysis (PCA) on the results describing the MIC and MBC of the tested EOs in relation to the most abundant secondary metabolites showed that the first two principal components (PCs) describe more than $95 \%$ of the dataset variability, while the principal components axis 1 (PCA1) describes more than $90 \%$ of the samples' variability. It can be observed that most of the variability is explained by the results describing the antibacterial potential in the case of Streptococcus spp., Enterobacter sakazakii, Klebsiella oxytoca, and Staphylococcus spp., as well as by the chemical composition in terms of carvacrol, trans- $\beta$-caryophyllene, and $\gamma$-terpinene content. Positioning of Thymus vulgaris EO samples in the negative part of PCA1 suggests that these samples, in relation to Thymus serpyllum $\mathrm{EO}$, are characterized by the presence of significant amounts of carvacrol, trans- $\beta$-caryophyllene, and p-cymene. Furthermore, the thyme EO showed stronger antibacterial potential against Streptococcus spp. ( $\beta$-hemolytic), Streptococcus spp. Enterobacter sakazakii, E. coli, and Klebsiella oxytoca in comparison with the wild thyme EO. On the other hand, Thymus serpyllum EO samples grouped in the positive part of PCA1 (as a result of higher amounts of thymol and $\gamma$-terpinen), and thus showed stronger antibacterial activity against Staphylococcus spp. (coagulase-negative) and Staphylococcus spp. (Figure 3). 


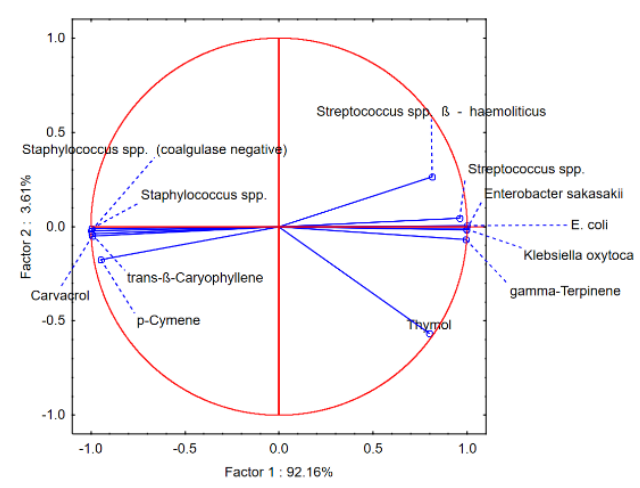

(a)

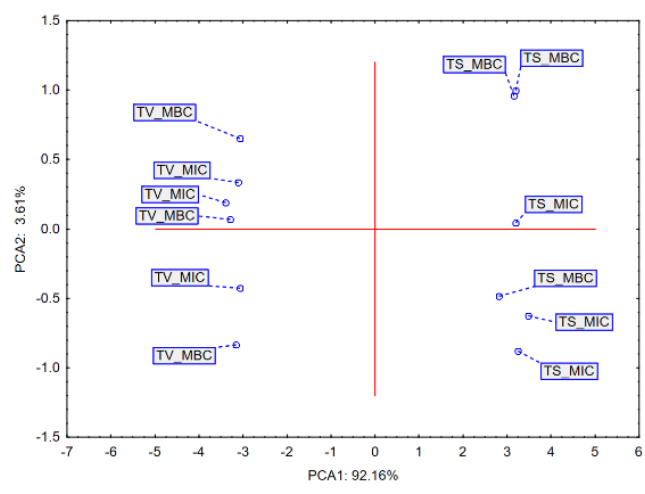

(b)

Figure 3. Results of principal components analysis (PCA): (a) loadings of the first two principal components; (b) position of the examined samples in the space defined by the first two principal components. TS, T. serpyllum; TV, T. vulgaris; MIC, minimum inhibitory concentration; MBC, minimal bactericidal concentration.

\section{Discussion}

Considering the importance of the issue of antimicrobial resistance (AMR), scientists are trying to find an alternative to antibiotics in mastitis therapy [33-35]. Recently, phytotherapy has been finding a place in the vast drug market owing to its capacity to prevent the development and spread of AMR. Phytotherapy in this way also reduces the economic losses in the dairy industry caused by rejection of milk due to antibiotic withdrawal time $[36,37]$.

In order to develop an EO-based pharmaceutical formulation, it is necessary to perform chemical composition analysis and testing of EOs against the most common mastitis pathogens.

Analysis of EOs' chemical composition in this study revealed that both tested essential oils are in accordance with the requirements prescribed by Ph. Eur. 10 (2020) [38] for thymol type of thyme EOs, with thymol ranging from 37 to $55 \%$ and carvacrol from 0.5 to $5.5 \%$. According to the pharmacopoeia, the official biological source of Thymus vulgaris EO is only the flowering aerial parts of Thymus vulgaris, T. zygis, or a mixture of both species, while T. serpyllum is the biological source of Serpylli herba. However, the content of thymol in the wild thyme EO is higher (54.17\%) than in the common thyme EO (45.22\%). Unlike thymol, the content of carvacrol is reversed (3.86\% in common thyme and $0.81 \%$ in wild thyme). There is a notable difference between the tested EOs in the content of $p$-cymene in common thyme (23.83\%) and wild thyme (16.66\%), but both EOs meet the quality criteria prescribed by the pharmacopoeia (14-28\%). On the other hand, the content of $\gamma$-terpinene (3.12\% for common thyme and $22.18 \%$ for wild thyme) does not comply with the pharmacopoeia requirements $(4-12 \%)$. According to the prescribed content of linalool (1.5-6.5\%) and terpinen-4-ol (0.1-2.5\%) established by the pharmacopoeia, T. vulgaris EO meets the requirements related to the chemical composition for thymol type EO $(2.55 \%$ for linalool and $1.42 \%$ for terpinen-4-ol). The results for T. vulgaris EO composition are also in line with previously published data $[20,21,39]$. However, because, in the wild thyme EO, several chemotypes are described [26-28], this oil could be defined as a thymol chemotype.

However, the chemical composition of T. vulgaris $\mathrm{EO}$ of commercial origin $[40,41]$, and from different regions [36-38] showed different thymol chemotypes, with the thymol being the more abundant compound.

It is well known that plants possess significant antioxidant potential, mainly attributed to the presence of different aromatic, phenolic, and flavonoid compounds [42]. Nowadays, the trends in food and cosmetic industry suggest the use of natural products, especially as a replacement for synthetic antioxidants [43]. Although EOs in all of the tested systems exhibited weaker free radical scavenging effects, it must be emphasized that the comparison of the antioxidant potential in the present study was performed between pure compounds 
and EOs, which are mixtures of different secondary metabolites, meaning that some of them do not possess potential for scavenging reactive oxygen species (ROS) and preventing biological membrane degradation. Regarding their toxicity, synthetic antioxidants are abused in some food and cosmetic products, especially tert-butylated hydroxytoluene (BHT) [44].

Regarding that fact, the EOs tested in our study showed notable antioxidant potential, similar to the results of other authors $[20,21,27,28,32,45]$, although the general comparison of the results obtained in different labs is sometimes difficult because of different experimental conditions and presentation of the results, different methods of antioxidant potential evaluation, and so on. In addition, in the case of various Thymus species EOs, the chemical composition plays a significant role in antioxidant effects as thymol and carvacrol are the main compounds responsible for RSC and inhibition of peroxidation of different lipids and biological membranes $[20,21]$. Both thymol and carvacrol demonstrate the ability to achieve a resonantly stable radical structure after donation of hydrogen atom or electrons to ROS, thus neutralizing the cascade of free radical reactions [42]. Hence, different chemotypes, especially of different species of wild thyme (T. serpyllum, T. marschallianus, T. jankae, T. longicaulis, T. lonidens, T. pannonicus, and so on), can show significantly weaker antioxidant effects [27]. As different plant-derived products have less toxicity and side effects compared with synthetic antioxidants, they can play an important role in the prevention of various diseases and syndromes where reactive oxygen species are involved [42]. They have also found their place as natural preservatives in the pharmaceutical, food, and cosmetic industry [43]. ROS production is linked with the inflammatory process and is provided by netrophils in milk [46].

The results obtained in this study indicated that the common thyme EO showed stronger antibacterial potential against Streptococcus spp. ( $\beta$-hemolytic), Streptococcus spp. Enterobacter sakazakii, E. coli, and Klebsiella oxytoca in comparison with the wild thyme EO. On the other hand, wild thyme EO samples grouped in the positive part of PCA1 (as a result of higher amounts of thymol and $\gamma$-terpinen), and thus showed stronger antibacterial activity against Staphylococcus spp. (coagulase-negative) and Staphylococcus spp. (Figure 3). The significant antimicrobial activity of T. vulgaris EO against Staphylococcus spp. isolated from bovine mastitis has been previously confirmed $[47,48]$. These studies reported phenolic compounds such as carvacrol and thymol as major constituents of the tested EO are responsible for their antimicrobial activities.

Phenolic compounds (carvacrol and thymol) account for $54.98 \%$ of the total oil in T. serpyllum EO and $49.08 \%$ in T. vulgaris EO. The antibacterial effect of the EOs tested in our study probably depends on these compounds, and a number of studies revealed that phenolic compounds, such as carvacrol and thymol, possess antibacterial activity [21,49-51]. Furthermore, the main constituents of the EOs tested in our study are monoterpenes (thymol, carvacrol, p-cymene, and $\gamma$-terpinene), which showed a remarkable inhibitory effect against different pathogens such as Staphylococcus aureus, Escherichia coli O157:H7, Salmonella Infantis, Bacillus cereus, and Clostridium perfringes [21,50,52]. From the chemical point of view, carvacrol and thymol represent structural isomers and possess differently located phenolic hydroxyl on the phenolic ring [53]. Some studies indicated that the hydroxyl group has a part in increasing their hydrophilic ability, helping them to dissolve in the microbial membrane and impair them [54-57].

Compared with carvacrol, thymol also possesses similar antibacterial activity, even though its hydroxyl group is located in a different position [58]. The thymol primary mode of antibacterial action is partly understood and it is probably similar to carvacrol. This mode of action results in structural and functional alterations in the cytoplasmic membrane that can damage the outer and inner membranes and interact with membrane proteins, as well as intracellular targets [59]. In contact with the cell membrane, thymol can modify membrane permeability, leading to the release of $\mathrm{K}^{+}$ions and ATP $[54,60,61]$. Some studies revealed that thymol integrates within the polar head-groups of the lipid bilayer, causing alterations of the cell membrane $[54,60,62]$. In contrast to the efficiency 
of monoterpenes with added oxygen molecules (carvacrol and thymol), monoterpene hydrocarbons p-cymene and $\gamma$-terpinene used separately do not demonstrate remarkable inhibitory effects against bacteria growth $[50,63]$.

However, several studies indicated that $p$-cymene can enhance the inhibitory effects of carvacrol when these two compounds are used together $[58,64,65]$. It was also shown that $p$-cymene, owing to its hydrophobic nature, greatly contributes to the cytoplasmic membrane swelling [61]. The findings obtained by Ultee, Bennik, and Moezelaar [61] indicated that $p$-cymene enabled carvacrol to be more easily transported into the cell. With respect to these findings, a slightly higher antibacterial effect of T. vulgaris $\mathrm{EO}$ obtained in this research could be accounted for by a slightly higher content of $p$-cymene.

Fratini et al., examining the efficiency of Thymus vulgaris L. ct. carvacrol and T. vulgaris L. ct. thymol), two selected mixtures of EOs, and two artificial mixtures of their main constituents (thymol, carvacrol, and p-cymene), against the bacterial strains involved in the pathogenesis of mastitis using the Kirby-Bauer method, confirmed that thymol and carvacrol as main constituents of tested $\mathrm{EO}$ are responsible for antibacterial activity. Moreover, the highest antibacterial effectiveness was obtained with the artificial mixture of pure constituents (carvacrol and thimol) with the addition of p-cymene [48].

This study revealed significant resistance of the most common mastitis pathogens to antimicrobials, indicating the importance of finding an alternative to antibiotic treatment in therapy of this disease. Moreover, it was shown that gram-negative pathogens (E. coli, Klebsiella oxytoca and Enterobacter sakazakii) are resistant to erythromycin, amoxycillin, and amoxicillin/clavulanic acid. This is in accordance with results of other studies, which determined resistance to the mentioned antimicrobials [66]. In addition, Streptococcus spp. isolated in this study showed resistance to trimethoprim/sulfamethoxazole, neomycin, enrofloxacin, tetracycline, lincomycin, and ceftriaxone, which is in line with the resistance determined in other studies [67].

Interestingly, although studies conducted so far highlighted the possibilities of EOs as a potential resistance-modifying agent, they provided limited evidence suggesting the spontaneous occurrence of resistance to EOs [68]. In fact, resistance of bacteria to EOs and their active components depends on their chemical composition, as well as their mechanism of action, which is specific and completely different compared with antibiotics. The antimicrobial activity of these natural substances has not been fully studied, but, owing to the proven ability of some EOs to inhibit bacterial cell wall synthesis, block transcription, $\beta$-lactamase production, biofilm formation, or efflux pump operation, they are considered to be useful in the treatment of infections caused by resistant microorganisms $[68,69]$. Besides, the difference between the mechanisms of resistance in EOs and antimicrobials is giving immense potential for the replacement of conventional antimicrobial therapy with phytotherapy.

\section{Material and Methods}

\subsection{Essential Oils}

In the present study, the essential oils of common (Thymus vulgaris L., Lamiaceae) and wild thyme (Thymus serpyllum L., Lamiaceae), commercially available on the Serbian market and produced by a certified manufacturer (Pharmanais d.o.o., Serbia), were evaluated in the study. Row plant material (Thymi folium and Serpylli herba) was sampled before distillation from the manufacturer and confirmed for identity. Voucher specimens (Tv-03/2020 and Ts$2 / 2020$, respectivelly) were deposited at the Herbarium of drugs of the Pharmacognosy and phytotherapy laboratory, Department of Pharmacy, Faculty of Medicine, University of Novi Sad. According to the certificate obtained from the manufacturer for both samples, essential oils were obtained using the internal steam distillation technique (Cellkraft AB, Sweden).

\subsection{Sampling Procedure}

The milk samples were collected from four Holstein-Friesian dairy farms located in Serbia. The number of cows on the farms varied, ranging from twenty to three hundred. The 
samples were taken from lactating animals with clinical and subclinical mastitis, without other health problems. Clinical mastitis was diagnosed by clinical examination of udder, while subclinical mastitis was confirmed using somatic cell count in the milk samples.

Bacteriological testing was performed by taking aseptic milk samples from all animals (clinical and subclinical mastitis) during the morning milking. The samples were then taken in sterile tubes marked with an ID number of the cow and stored at $4{ }^{\circ} \mathrm{C}$. Afterwards, the samples were processed at the Laboratory for Milk Hygiene at the Department of Veterinary Medicine, Faculty of Agriculture, University of Novi Sad. The samples were inoculated on $2 \%$ blood agar, using a platinum loop $(0.01 \mathrm{~mL})$, followed by incubation of the samples for $48 \mathrm{~h}$ at $37^{\circ} \mathrm{C}$. Biochemical and cultural characteristics of the grown microorganisms were taken into account during their determination. Isolation and identification of bacterial strain from milk samples was conducted using microbiological procedures for the diagnosis of udder infection published by National Mastitis Council. A loopful of milk sample was streaked on blood agar (Oxoid) and then subcultured on the following selective media: Mannitol Salt Agar, Edwards Agar, Salmonella-Shigella Agar, and MacConkey Agar. Then, plates were incubated aerobically at $37^{\circ} \mathrm{C}$ for $24 \mathrm{~h}$. After incubation, the plates were examined for colony morphology, pigmentation, and hemolytic characteristics at 24-48 h. Catalase test was applied for distinguishing between staphylococci and other Gram-positive cocci, mannitol fermentation test, coagulase test (either positive or negative), hemolytic pattern, and colony morphology. The isolates were confirmed by biochemical tests: oxidase activity, acid production (lactose sucrose and glucose fermentation), indole production, Voges-Proskauer, and hydrogen sulfide production. In addition, each strain was confirmed using Analytical Profile Index API-20 tests (API, bio Meraux, France). To isolate staphylococci, listed media were used: blood agar, nutrient agar, Ziehl-Neelsen, MSA, for E. coli isolation nutrient agar, MacConkey agar, and API 25 were used. For streptococci, Edwards agar and esculin were used. Of the phenotypic characteristics for staphylococci, the occurrence of $\alpha$ and $\beta$ hemolysis and, for E. coli, there were pink colonies with precipitation. For streptococci determination, hydrolysis of esculin was used.

\subsection{Antibiotic Susceptibility Testing of Mastitis-Associated Bacteria}

The antibiotic susceptibility patterns for the 16 mastitis-associated bacteria were established in vitro, following the Kirby-Bauer disc diffusion method, on Mueller-Hinton agar (Oxoid) [70]. Antibiotic susceptibility testing was conducted using commercially available antibiotic disks (Bioanalyse) in the following concentrations: ampicillin $(10 \mu \mathrm{g})$; streptomycin $(10 \mu \mathrm{g})$; gentamicin $(10 \mu \mathrm{g})$; trimethoprim/sulphamethoxazole $(1.25 / 23.75 \mu \mathrm{g})$; enrofloxacin $(5 \mu \mathrm{g})$; and ceftriaxone $(30 \mu \mathrm{g})$. The isolates and reference strains were inoculated on nutrient broth separately and incubated aerobically at $37^{\circ} \mathrm{C}$. After overnight incubation, the bacterial suspension was vortexed and diluted to a turbidity equivalent to that of $0.5 \mathrm{McF}$ arland standards. The bacterial suspension was then spread onto the surface of the Mueller-Hinton agar to make confluent growth. Antibiotic discs were immediately placed on the surface of the agar plate using forceps and incubated aerobically at $37^{\circ} \mathrm{C}$ for $16 \mathrm{~h}$. Inhibition zones for various isolates were measured and interpreted as sensitive, intermediate, or resistant according to the Clinical Laboratory Standards Institute (CLSI) [71,72].

\subsection{EOs Chemical Composition Analysis}

The qualitative and quantitative analysis of the EOs was carried out on HP-5MS capillary column $(30 \mathrm{~m} \times 0.25 \mathrm{~mm}$; film thickness $0.25 \mu \mathrm{m})$ on Agilent 6890B gas chromatograph coupled with flame ionization detector (GC-FID) instrument coupled to Agilent 5977 mass spectrometry detector (MSD) (Agilent Technologies Inc, Santa Clara, CA, USA, USA). The samples were injected in split mode 1:20, at an inlet temperature of $220^{\circ} \mathrm{C}$. The oven temperature was set at $60{ }^{\circ} \mathrm{C}$ and increased at a rate of $3{ }^{\circ} \mathrm{C} / \mathrm{min}$ up to $246{ }^{\circ} \mathrm{C}$. Helium was the carrier gas $(1 \mathrm{~mL} / \mathrm{min})$, while the temperature of the MSD transfer line was set to $230{ }^{\circ} \mathrm{C}$. 
Mass spectral data were collected in scan mode $(m / z=50-550)$, while the identification of compounds was performed using NIST (v14, National Institute of Standards and Technology, Gaithersburg, MD, USA) mass spectral database and comparison of relative retention indices (RT), as well as literature data [73].

\subsection{EOs' Antioxidant Potential Evaluation}

The antioxidant potential of the commercial EOs of wild (Thymus serpyllum) and common thyme (Thymus vulgaris) was evaluated in five in vitro assays, as single models are not recommended for evaluation because of the complex composition of different plant extracts [74]. The potential of the EOs to neutralize 2,2-diphenyl-1-picrylhydrazyl (DPPH), hydroxyl $(\mathrm{OH})$ and nitroso (NO) radicals was assessed by previously described spectrophotometric methods [32]. Moreover, the ability of the examined EOs to inhibit the processes of lipid peroxidation (LP) is evaluated, using liposomes emulsion as a test model [20]. The potential of the examined EOs to reduce $\mathrm{Fe}^{3+}$ (ferric reduction antioxidant potential-FRAP test) was assessed by the method described by Lesjak et al. [45], as it is a model correlating with the neutralization of hypochlorite and peroxynitrite anion [75]. The results obtained in the FRAP assay were expressed as ascorbic acid equivalents (AAEs) based on the previously constructed calibration curve for ascorbic acid. For each sample, four replicates were recorded in all test-systems. Synthetic antioxidants, including ascorbic acid (AA), propyl gallate (PG), and tert-butylated hydroxytoluene (BHT), were tested under the same experimental conditions as positive control for antioxidant potential of the tested EOs.

\subsection{EOs' Effectiveness Determination against Mastitis-Associated Bacteria}

EOs' effectiveness on planktonically grown bacteria was determined according to the Clinical Laboratory Standards [76] with slight modifications. The bacterial suspensions were prepared using overnight cultures and adjusted to $0.5 \mathrm{Mc}$ Farland standard turbidity (corresponding to $1 \times 10^{8} \mathrm{CFU} / \mathrm{mL}$ ), using a densitometer DEN-1 (Biosan, Riga, Latvia). All tests were performed in Muller-Hinton broth (MHB) (Lab M, International Diagnostics Group Plc, Bury, Lancashire, UK). MHB supplemented with 0.5\% Tween 80 (Polyoxyethylenesorbitan monooleate, HiMedia Laboratories Pvt. Ltd., Mumbai, India) was used for dissolving the EOs, as well as for their dilution to the concentration ranging from 1000 to $0.9 \mathrm{mg} / \mathrm{mL}$. Twenty-microliter aliquots of each tested EO were added to 96-well microtiter plates. Afterward, aliquots of $160 \mu \mathrm{L}$ of MHB were added to each well. As the final step, $20 \mu \mathrm{L}$ of the standardized bacterial suspension was inoculated into each well. The test was performed in a total volume of $200 \mu \mathrm{L}$ with final EOs' concentrations ranging from 100 to $0.09 \mathrm{mg} / \mathrm{mL}$, while the final microbial concentration was $10^{7} \mathrm{CFU} / \mathrm{mL}$. The plates were incubated at $37^{\circ} \mathrm{C}$ for $24 \mathrm{~h}$. The same tests were performed simultaneously for growth control (MHB + test organism), negative control (MHB + solvent + test organism), and sterility control (MHB + test oil).

Following the incubation, $10 \mu \mathrm{L}$ of the resazurin solution $(0.01 \%)$ (Sigma-Aldrich, St Louis, MO, USA) was added to each well. Subsequently, the plates were further incubated at $37^{\circ} \mathrm{C}$ for $6 \mathrm{~h}$ (in darkness). After visual examination, the plates were additionally incubated for $18 \mathrm{~h}$. Change of color from blue (oxidized) to pink (reduced) indicated the growth of bacteria. On completion of the incubation, wells without the color change (blue color of resazurin remained unchanged) were scored as above the minimum inhibitory concentration (MIC) value. MIC was defined as the lowest concentration at which the color change occurred $[77,78]$.

Referring to the results of the MIC assay, the wells showing complete absence of growth were identified and $100 \mu \mathrm{L}$ of the solutions from each well was transferred to plate count agar plates (PCA) (Lab M, International Diagnostics Group Plc, Bury, Lancashire, UK) and incubated at $37{ }^{\circ} \mathrm{C}$ for $24 \mathrm{~h}$. The minimal bactericidal concentration (MBC) was defined as the lowest concentration of the EOs at which $99.9 \%$ of the inoculated bacteria were killed. 


\subsection{Data Analysis}

The results obtained in the study were processes by MS Office Excel v2019 (Microsoft Corporation, Redmond, WA, USA) and Statsoft Statistica v12.5 (Hamburg, Germany) software. The values were expressed as the mean values corrected by standard deviation (SD). Methods of univariate and multivariate statistical analysis (MANOVA, pincipal component analysis (PCA) and correspondence analysis (CA)) were applied for comprehensive evaluation of the relations in the obtained dataset.

\section{Conclusions}

This study highlighted that two thyme (Thymus serpyllum and T. vulgaris) EOs can be used in the development of pharmaceutical formulation as an alternative to conventional mastitis therapy, owing to the EOs' chemical composition, antioxidant potential, and effectiveness against mastitis-associated bacteria. Further research on dairy farms is needed to conduct clinical trials of EO-based formulation. Moreover, additional studies should explore their toxicity to mammalian cells and drug-like properties (pharmacokinetic and pharmacodynamic) to determine their potential as therapeutic agents. Finally, further studies also need to compare the economic aspects of the conventional versus herbal treatment of mastitis, as well as the combination of EOs with common antibiotics used in the treatment of mastitis.

Author Contributions: Conceptualization, Z.K., I.Č., and B.B.; Formal analysis, N.K.; Investigation, Z.K., M.R., I.Č., N.K., and B.B.; Methodology, Z.K. and B.B.; Supervision, Z.K.; Validation, I.Č. and N.K.; Writing—original draft, Z.K., M.R., I.C.., N.K., and B.B.; Writing—review \& editing, Z.K., M.R., I.C., N.K., and B.B.; Funding acquisition, Z.K. All authors have read and agreed to the published version of the manuscript.

Funding: This research was supported by the Science Fund of the Republic of Serbia, PROMIS, \#GRANT No 6066966, InfoBomat.

Institutional Review Board Statement: Not applicable.

Informed Consent Statement: Not applicable.

Data Availability Statement: Data is contained within the article.

Conflicts of Interest: The authors declare no conflict of interest.

\section{References}

1. Gruet, P.; Maincent, P.; Berthelot, X.; Kaltsatos, V. Bovine mastitis and intramammary drug delivery: Review and perspectives. Adv. Drug Deliv. Rev. 2001, 50, 245-259. [CrossRef]

2. Garcia, S.N.; Osburn, B.I.; Cullor, J.S. A one health perspective on dairy production and dairy food safety. One Health 2019, 7, 100086. [CrossRef]

3. Halasa, T.; Huijps, K.; Osteras, O.; Hogeveen, H. Economic effects of bovine mastitis and mastitis management: A review. Vet. Q. 2007, 29, 18-31. [CrossRef] [PubMed]

4. Drašković, B.; Stošić, I.; Rajković, Z. Tržišna struktura i nestašice mleka u Srbiji. In Agrarna i ruralna politika u Srbiji: Nužnost ubrzanja reformi: Tematski zbornik; DAES Društvo agrarnih ekonomista Srbije: Beograd, Serbia, 2011; pp. 65-79.

5. Hristov, S.; Stanković, B.M.; Relić, R. Klinički i subklinički mastitis u krava. Biotechnol. Anim. Husb. 2005, 21, 29-39. [CrossRef]

6. Kim, T.; Heald, C.W. Inducing inference rules for the classification of bovine mastitis. Comput. Electron. Agric. 1999, 23, 27-42. [CrossRef]

7. Zadoks, R.; Fitzpatrick, J. Changing trends in mastitis. Ir. Vet. J. 2009, 62 (Suppl. 4), S59-S70. [CrossRef] [PubMed]

8. Boboš, S.; Vidić, B. Mlečna žlezda preživara, morfologija, patologija, terapija; Univeryitet u Novom Sadu, Poljoprivredni fakultet: Novi Sad, Serbia, 2005; pp. 57-91.

9. Krömker, V.; Leimbach, S. Mastitis treatment- Reduction in antibiotic usage in dairy cows. Reprod Dom Anim 2017, 52, 21-29. [CrossRef]

10. Erskine, R.J.; Wagner, S.; DeGraves, F.J. Mastitis therapy and pharmacology. Vet. Clin. North Am. Food Anim. 2003, 19, 109-138. [CrossRef]

11. Gupta, R.; Kumar, S.; Khurana, R. Essential oils and mastitis in dairy animals: A review. Haryana Vet. 2020, 59, 1-9.

12. Sandegren, L. Selection of antibiotic resistance at very low antibiotic concentrations. Upsala J. Med. Sci. 2014, 119, $103-107$. [CrossRef] [PubMed] 
13. Dingwell, R.T.; Kelton, D.F.; Leslie, K.E. Management of the dry cow in control of peripartum disease and mastitis. Vet. Clin. N. Am. Food Anim. 2003, 19, 235-265. [CrossRef]

14. Oliver, S.P.; Jayarao, B.M.; Almeida, R.A. Foodborne pathogens in milk and the dairy farm environment: Food safety and public health implications. Foodborne Pathog. Dis. 2005, 2, 115-129. [CrossRef]

15. Fusco, V.; Chieffi, D.; Fanelli, F.; Logrieco, A.F.; Cho, G.S.; Kabisch, J.; Böhnlein, C.; Franz, C.M.A.P. Microbial quality and safety of milk and milk products in the 21st century. Compr. Rev. Food Sci. Food Saf. 2020, 19, 2013-2049. [CrossRef]

16. WHO. Global Action Plan on Antimicrobial Resistance; World Health Organization: Geneva, Switzerland, 2015 ; pp. 1-28.

17. Kokoska, L.; Kloucek, P.; Leuner, O.; Novy, P. Plant-Derived Products as Antibacterial and Antifungal Agents in Human Health Care. Curr. Med. Chem. 2019, 26, 5501-5541. [CrossRef] [PubMed]

18. O'Bryan, C.A.; Pendleton, S.J.; Crandall, P.G.; Ricke, S.C. Potential of Plant Essential Oils and Their Components in Animal Agriculture - in vitro Studies on Antibacterial Mode of Action. Front. Vet. Sci. 2015, 2. [CrossRef] [PubMed]

19. Ananda Baskaran, S.; Kazmer, G.W.; Hinckley, L.; Andrew, S.M.; Venkitanarayanan, K. Antibacterial effect of plant-derived antimicrobials on major bacterial mastitis pathogens in vitro. Int. J. Dairy Sci. 2009, 92, 1423-1429. [CrossRef] [PubMed]

20. Bozin, B.; Mimica-Dukic, N.; Simin, N.; Anackov, G. Characterization of the Volatile Composition of Essential Oils of Some Lamiaceae Spices and the Antimicrobial and Antioxidant Activities of the Entire Oils. J. Agric. Food Chem. 2006, 54, 1822-1828. [CrossRef]

21. Gavaric, N.; Mozina, S.S.; Kladar, N.; Bozin, B. Chemical Profile, Antioxidant and Antibacterial Activity of Thyme and Oregano Essential Oils, Thymol and Carvacrol and Their Possible Synergism. J. Essent. Oil-Bear. Plants. 2015, 18, 1013-1021. [CrossRef]

22. Lemos, M.F.; Lemos, M.F.; Pacheco, H.P.; Guimarães, A.C.; Fronza, M.; Endringer, D.C.; Scherer, R. Seasonal variation affects the composition and antibacterial and antioxidant activities of Thymus vulgaris. Ind. Crops Prod. 2017, 95, 543-548. [CrossRef]

23. Nikolić, M.; Glamočlija, J.; Ferreira, I.C.F.R.; Calhelha, R.C.; Fernandes, Â.; Marković, T.; Marković, D.; Giweli, A.; Soković, M. Chemical composition, antimicrobial, antioxidant and antitumor activity of Thymus serpyllum L., Thymus algeriensis Boiss. and Reut and Thymus vulgaris L. essential oils. Ind. Crops Prod. 2014, 52, 183-190. [CrossRef]

24. Langeveld, W.T.; Veldhuizen, E.J.; Burt, S.A. Synergy between essential oil components and antibiotics: A review. Crit. Rev. Microbiol. 2014, 40, 76-94. [CrossRef] [PubMed]

25. Hemaiswarya, S.; Kruthiventi, A.K.; Doble, M. Synergism between natural products and antibiotics against infectious diseases. Phytomedicine 2008, 15, 639-652. [CrossRef]

26. Malankina, E.L.; Kozlovskaya, L.N.; Kuzmenko, A.N.; Evgrafov, A.A. Determination of the Component Composition of Essential Oil of Thyme Species by the Method of Gas Chromatography. Mosc. Univ. Chem. Bull. 2020, 74, 310-314. [CrossRef]

27. Ćavar-Zeljković, S.; Maksimović, M. Chemical composition and bioactivity of essential oil from Thymus species in Balkan Peninsula. Phytochem. Rev. 2015, 14, 335-352. [CrossRef]

28. Tohidi, B.; Rahimmalek, M.; Arzani, A. Essential oil composition, total phenolic, flavonoid contents, and antioxidant activity of Thymus species collected from different regions of Iran. Food Chem. 2017, 220, 153-161. [CrossRef] [PubMed]

29. Helal, I.M.; El-Bessoumy, A.; Al-Bataineh, E.; Joseph, M.R.P.; Rajagopalan, P.; Chandramoorthy, H.C.; Ben Hadj Ahmed, S. Antimicrobial Efficiency of Essential Oils from Traditional Medicinal Plants of Asir Region, Saudi Arabia, over Drug Resistant Isolates. Biomed. Res. Int. 2019, 2019, 8928306. [CrossRef] [PubMed]

30. Acimovic, M.; Zoric, M.; Zheljazkov, V.D.; Pezo, L.; Cabarkapa, I.; Stankovic Jeremic, J.; Cvetkovic, M. Chemical Characterization and Antibacterial Activity of Essential Oil of Medicinal Plants from Eastern Serbia. Molecules 2020, 25, 5482. [CrossRef]

31. Radinović, M.; Davidov, I.; Kovačević, Z.; Stojanović, D.; Galfi, A.; Erdeljan, M. Basic Principles of Mastitis Therapy. Vet. J. Republic Srpska. 2019, 19. [CrossRef]

32. Bozin, B.; Kladar, N.; Grujic, N.; Anackov, G.; Samojlik, I.; Gavaric, N.; Conic, B.S. Impact of origin and biological source on chemical composition, anticholinesterase and antioxidant properties of some St. John's wort species (Hypericum spp., Hypericaceae) from the Central Balkans. Molecules 2013, 18, 11733-11750. [CrossRef]

33. Mushtaq, S.; Shah, A.M.; Shah, A.; Lone, S.A.; Hussain, A.; Hassan, Q.P.; Ali, M.N. Bovine mastitis: An appraisal of its alternative herbal cure. Microb. Pathog. 2018, 114, 357-361. [CrossRef]

34. Yang, W.-T.; Ke, C.-Y.; Wu, W.-T.; Lee, R.-P.; Tseng, Y.-H. Effective Treatment of Bovine Mastitis with Intramammary Infusion of Angelica dahurica and Rheum officinale Extracts. Evid. Based Complementary Altern. Med. 2019, 2019, 7242705. [CrossRef] [PubMed]

35. Lopes, T.S.; Fontoura, P.S.; Oliveira, A.; Rizzo, F.A.; Silveira, S.; Streck, A.F. Use of plant extracts and essential oils in the control of bovine mastitis. Res. Vet. Sci. 2020, 131, 186-193. [CrossRef]

36. McGaw, L. Use of Plant-Derived Extracts and Essential Oils against Multidrug-Resistant Bacteria Affecting Animal Health and Production. In Fighting Multidrug Resistance with Herbal Extracts, Essential Oils and Their Components; Rai, M.K., Kon, K.V., Eds.; Academic Press: San Diego, CA, USA, 2013; pp. 191-203. Available online: https:/ /doi.org/10.1016/B978-0-12-398539-2.00013-6 (accessed on 12 December 2020).

37. Doehring, C.; Sundrum, A. The informative value of an overview on antibiotic consumption, treatment efficacy and cost of clinical mastitis at farm level. Prev. Vet. Med. 2019, 165, 63-70. [CrossRef] [PubMed]

38. EDQM. European Pharmacopoeia 10.3; The European Directorate for the Quality of Medicines \& HealthCare, Council of Europe: Brusselles, Belgium, 2020; pp. 1648-1650. 
39. Bogavac, M.; Karaman, M.; Janjusevic, L.; Sudji, J.; Radovanovic, B.; Novakovic, Z.; Simeunovic, J.; Bozin, B. Alternative treatment of vaginal infections-in vitro antimicrobial and toxic effects of Coriandrum sativum L. and Thymus vulgaris L. essential oils. J. Appl. Microbiol. 2015, 119, 697-710. [CrossRef] [PubMed]

40. Pinto, L.; Cefola, M.; Bonifacio, M.A.; Cometa, S.; Bocchino, C.; Pace, B.; De Giglio, E.; Palumbo, M.; Sada, A.; Logrieco, A.F.; et al. Effect of red thyme oil (Thymus vulgaris L.) vapours on fungal decay, quality parameters and shelf-life of oranges during cold storage. Food Chem. 2021, 336, 127590. [CrossRef] [PubMed]

41. Pinto, L.; Bonifacio, M.A.; De Giglio, E.; Cometa, S.; Logrieco, A.F.; Baruzzi, F. Unravelling the Antifungal Effect of Red Thyme Oil (Thymus vulgaris L.) Compounds in Vapor Phase. Molecules 2020, 25, 4761. [CrossRef]

42. Mimica-Dukic, N.; Bozin, B. Mentha L. species (Lamiaceae) as promising sources of bioactive secondary metabolites. Curr. Pharm. Des. 2008, 14, 3141-3150. [CrossRef]

43. Caleja, C.; Barros, L.; Antonio, A.L.; Oliveira, M.B.; Ferreira, I.C. A comparative study between natural and synthetic antioxidants: Evaluation of their performance after incorporation into biscuits. Food Chem. 2017, 216, 342-346. [CrossRef]

44. Lanigan, R.S.; Yamarik, T.A. Final report on the safety assessment of BHT(1). Int. J. Toxicol. 2002, 21, 19-94. [CrossRef]

45. Lesjak, M.M.; Beara, I.N.; Orčić, D.Z.; Anačkov, G.T.; Balog, K.J.; Francišković, M.M.; Mimica-Dukić, N.M. Juniperus sibirica Burgsdorf. as a novel source of antioxidant and anti-inflammatory agents. Food Chem. 2011, 124, 850-856. [CrossRef]

46. Molinari, P.C.C.; Blagitz, M.G.; Libera, A.M.M.P.D.; Batista, C.F.; Souza, F.N. Intracellular reactive oxygen species production and phagocytosis of Staphylococcus aureus by milk neutrophils as tool to diagnose mastitis and identify susceptible dairy cows. Pesqui. Vet. Bras. 2018, 38, 659-664. [CrossRef]

47. Dal Pozzo, M.; Santurio, D.F.; Rossatto, L.; Vargas, A.C.; Alves, S.H.; Loreto, E.S.; Viegas, J. Activity of essential oils from spices against Staphylococcus spp. isolated from bovine mastitis. Arq. Bras. Med. Vet. Zootec. 2011, 63, 1229-1232. [CrossRef]

48. Fratini, F.; Casella, S.; Leonardi, M.; Pisseri, F.; Ebani, V.V.; Pistelli, L.; Pistelli, L. Antibacterial activity of essential oils, their blends and mixtures of their main constituents against some strains supporting livestock mastitis. Fitoterapia. 2014, 96, 1-7. [CrossRef] [PubMed]

49. Burt, S. Essential oils: Their antibacterial properties and potential applications in foods-a review. Int. J. Food Microbiol. 2004, 94, 223-253. [CrossRef]

50. Burt, S.A.; Vlielander, R.; Haagsman, H.P.; Veldhuizen, E.J.A. Increase in Activity of Essential Oil Components Carvacrol and Thymol against Escherichia coli O157:H7 by Addition of Food Stabilizers. J. Food Prot. 2005, 68, 919-926. [CrossRef]

51. Veldhuizen, E.J.; Tjeerdsma-van Bokhoven, J.L.; Zweijtzer, C.; Burt, S.A.; Haagsman, H.P. Structural requirements for the antimicrobial activity of carvacrol. J. Agric. Food. Chem. 2006, 54, 1874-1879. [CrossRef]

52. Du, E.; Gan, L.; Li, Z.; Wang, W.; Liu, D.; Guo, Y. In vitro antibacterial activity of thymol and carvacrol and their effects on broiler chickens challenged with Clostridium perfringens. J. Anim. Sci. Biotechnol. 2015, 6, 58. [CrossRef]

53. Hayashi, M.A.; Bizerra, F.C.; Da Silva, P.I., Jr. Antimicrobial compounds from natural sources. Front. Microbiol. 2013,4 , 195. [CrossRef]

54. Xu, J.; Zhou, F.; Ji, B.P.; Pei, R.S.; Xu, N. The antibacterial mechanism of carvacrol and thymol against Escherichia coli. Lett. Appl. Microbiol. 2008, 47, 174-179. [CrossRef]

55. Sikkema, J.; De Bont, J.A.M.; Poolman, B. Mechanisms of membrane toxicity of hydrocarbons. Microbiol. Rev. 1995, 59, 201-222. [CrossRef]

56. Nazzaro, F.; Fratianni, F.; De Martino, L.; Coppola, R.; De Feo, V. Effect of Essential Oils on Pathogenic Bacteria. Pharmaceuticals 2013, 6, 1451-1474. [CrossRef] [PubMed]

57. Marinelli, L.; Di Stefano, A.; Cacciatore, I. Carvacrol and its derivatives as antibacterial agents. Phytochem. Rev. 2018, 17, 903-921. [CrossRef]

58. Ultee, A.; Slump, R.A.; Steging, G.; Smid, E.J. Antimicrobial activity of carvacrol toward Bacillus cereus on rice. J. Food Prot. 2000, 63, 620-624. [CrossRef]

59. Chouhan, S.; Sharma, K.; Guleria, S. Antimicrobial Activity of Some Essential Oils-Present Status and Future Perspectives. Medicines 2017, 4, 58. [CrossRef]

60. Lambert, R.J.W.; Skandamis, P.N.; Coote, P.J.; Nychas, G.J.E. A study of the minimum inhibitory concentration and mode of action of oregano essential oil, thymol and carvacrol. J. Appl. Microbiol. 2001, 91, 453-462. [CrossRef] [PubMed]

61. Ultee, A.; Bennik, M.H.; Moezelaar, R. The phenolic hydroxyl group of carvacrol is essential for action against the food-borne pathogen Bacillus cereus. Appl. Environ. Microbiol. 2002, 68, 1561-1568. [CrossRef]

62. Helander, I.K.; Alakomi, H.L.; Latva-Kala, K.; Mattila-Sandholm, T.; Pol, I.; Smid, E.J.; von Wright, A. Characterization of the action of selected essential oil components on Gram-negative bacteria. J. Agric. Food Chem. 1998, 46, 3590-3595. [CrossRef]

63. Dorman, H.J.D.; Deans, S.G. Antimicrobial agents from plants: Antibacterial activity of plant volatile oils. J. Appl. Microbiol. 2000, 88, 308-316. [CrossRef]

64. Cristani, M.; D’Arrigo, M.; Mandalari, G.; Castelli, F.; Sarpietro, M.G.; Micieli, D.; Venuti, V.; Bisignano, G.; Saija, A.; Trombetta, D. Interaction of four monoterpenes contained in essential oils with model membranes: Implications for their antibacterial activity. J. Agric. Food Chem. 2007, 55, 6300-6308. [CrossRef]

65. Marchese, A.; Arciola, C.R.; Barbieri, R.; Silva, A.S.; Nabavi, S.F.; Tsetegho Sokeng, A.J.; Izadi, M.; Jafari, N.J.; Suntar, I.; Daglia, M.; et al. Update on Monoterpenes as Antimicrobial Agents: A Particular Focus on p-Cymene. Materials 2017, 10, 947. [CrossRef]

66. Belmar-Liberato, R.; Gonzalez-Canga, A.; Tamame-Martin, P.; Escribano-Salazar, M. Amoxicillin and amoxicillin-clavulanic acid resistance in veterinary medicine—-the situation in Europe: A review. Vet. Med. (Praha) 2011, 56, 473-485. [CrossRef] 
67. Supre, K.; Lommelen, K.; De Meulemeester, L. Antimicrobial susceptibility and distribution of inhibition zone diameters of bovine mastitis pathogens in Flanders, Belgium. Vet. Microbiol. 2014, 171, 374-381. [CrossRef] [PubMed]

68. Yap, P.S.; Yiap, B.C.; Ping, H.C.; Lim, S.H. Essential oils, a new horizon in combating bacterial antibiotic resistance. Open Microbiol. J. 2014, 8, 6-14. [CrossRef] [PubMed]

69. Cuaron, J.A.; Dulal, S.; Song, Y.; Singh, A.K.; Montelongo, C.E.; Yu, W.; Nagarajan, V.; Jayaswal, R.K.; Wilkinson, B.J.; Gustafson, J.E. Tea tree oil-induced transcriptional alterations in Staphylococcus aureus. Phytother. Res. 2013, 27, 390-396. [CrossRef]

70. Hudzicki, J. Kirby-Bauer Disk Diffusion Susceptibility Protocol; American Society for Microbiology (ASM): Washington, DC, USA, 2009; Available online: https:/ / www.asmscience.org/docserver/fulltext/education/protocol/protocol.3189.pdf?expires=1613 515898\&id=id\&accname=guest\&checksum=835F5125F08BB2AB46FF21C23963C9B7 (accessed on 1 December 2020).

71. CLSI. Performance Standards for Antimicrobial Disk and Dilution Susceptibility Tests for Bacteria Isolated from Animals, 3rd ed.; CLSI: Wayne, PA, USA, 2008.

72. CLSI. Performance Standards for Antimicrobial Disk Susceptibility Tests; Approved standard M02-A12; CLSI: Wayne, PA, USA, 2012.

73. Adams, R.P. Identification of Essential Oil Components by Gas Chromatography/Mass Spectrometry, 4th ed.; Allured Publishing Corporation: Carol Stream, IL, USA, 2007.

74. Nuutila, A.M.; Puupponen-Pimiä, R.; Aarni, M.; Oksman-Caldentey, K.-M. Comparison of antioxidant activities of onion and garlic extracts by inhibition of lipid peroxidation and radical scavenging activity. Food Chem. 2003, 81, 485-493. [CrossRef]

75. MacDonald-Wicks, L.K.; Wood, L.G.; Garg, M.L. Methodology for the determination of biological antioxidant capacity in vitro: A review. J. Sci. Food Agric. 2006, 86, 2046-2056. [CrossRef]

76. CLSI. Methods for Dilution Antimicrobial Susceptibility Tests for Bacteria That Grow Aerobically, 11th ed.; Approved Standard document M07; Clinical and Laboratory Standards Institute: Wayne, PA, USA, 2018; Available online: https://clsi.org/media/1928/m0 7ed11_sample.pdf (accessed on 1 December 2020).

77. Elshikh, M.; Ahmed, S.; Funston, S.; Dunlop, P.; McGaw, M.; Marchant, R.; Banat, I.M. Resazurin-based 96-well plate microdilution method for the determination of minimum inhibitory concentration of biosurfactants. Biotechnol. Lett. 2016, 38, 1015-1019. [CrossRef] [PubMed]

78. Čabarkapa, I.; Čolović, R.; Đuragić, O.; Popović, S.; Kokić, B.; Milanov, D.; Pezo, L. Anti-biofilm activities of essential oils rich in carvacrol and thymol against Salmonella Enteritidis. Biofouling 2019, 35, 361-375. [CrossRef] [PubMed] 